\title{
Hypoxia and inflammatory synovitis: observations and speculation
}

\author{
C R Stevens, R B Williams, A J Farrell, D R Blake
}

In recent years considerable research interest has been directed at studying the biological consequences of tissue hypoxia. As this work progresses it becomes increasingly apparent that tissue hypoxia has complex biological consequences. Much is now known about the natural defences of the body to hypoxia, including heat shock protein synthesis and angiogenesis. These systems are normally under rigid control, but this would seem not so in the rheumatoid joint. This accumulation of knowledge has prompted the belated reawakening of interest in joint hypoxia; it is now clear that an understanding of the physiological and pathological effects of joint hypoxia is of great importance to both clinical and research rheumatology.

This review outlines joint hypoxia from a historical perspective and offers explanations for the phenomenon. Some of the more pertinent implications of hypoxia in the context of inflammatory synovitis are discussed.

\section{The evidence}

SYNOVIAL FLUID

A major advantage in the assessment of joint physiology both in health and disease is the accessibility of synovial fluid from the larger joints. Accordingly, many comparative studies have been performed. In 1970 Lund-Olesen reported the results of a major survey comprising synovial fluid samples from 85 rheumatoid knees. ${ }^{1}$ The mean rheumatoid synovial fluid oxygen tension $\left(\mathrm{Po}_{2}\right)$ was found to be $27 \mathrm{mmHg}$, significantly lower than in acute traumatic effusions (mean $63 \mathrm{mmHg}$ ), although osteoarthritic knees were often hypoxic (mean 43 $\mathrm{mmHg})$. Treuhaft and McCarty, ${ }^{2}$ in a similar study of 55 rheumatoid patients, agreed with Lund-Olesen in finding that $27 \%$ of rheumatoid knees show profound hypoxia with a $\mathrm{Po}_{2}$ less than $15.2 \mathrm{mmHg}$. Other workers have independently verified this phenomenon. In addition to a low $\mathrm{PO}_{2}$, many studies have shown alterations in rheumatoid synovial fluid physiology which would be expected in a hypoxic state-namely, a raised carbon dioxide tension $\left(\mathrm{PCO}_{2}-\right.$ up to $150 \mathrm{mmHg}$ ), raised lactate (up to $10 \mathrm{mmol} / \mathrm{l}$ ), lowered glucose, and acidosis $(\mathrm{pH}$ as low as 6.6). ${ }^{3-11}$ The most notable study summarising these changes is by Falchuk, ${ }^{3}$ who showed that joints with the lowest $\mathrm{Po}_{2}$ (as low as $9 \mathrm{mmHg}$ ) also exhibited large increases in $\mathrm{PCO}_{2}$ and lactate; the same joints showed severe microvascular obliteration in the synovial membrane.
It is important to note that physiological measurements in synovial fluid can vary with the patient's activity. This is evident from a recent study, which showed that movement of an inflamed joint can induce significant further decrease in $\mathrm{Po}_{2}$ from a resting baseline. ${ }^{12}$ This observation has particular relevance to the concept of joint 'ischaemia-reperfusion' injury.

\section{SYNOVIAL MORPHOLOGY}

The sequence of pathological changes in rheumatoid arthritis is closely associated with alterations in the synovial microvasculature. From the mid-eighteenth century to date there have been many detailed subjective descriptions of synovial morphology in health and disease. Much of the described microvascular derangement in synovitis would seem to be both a consequence and cause of further hypoxia. The hypoxia of multilamination of vascular basement membrane, characteristic of rheumatoid arthritis, ${ }^{13}$ is seen in other vascular beds in response to hypoxia. ${ }^{14}$ It also imposes a barrier to oxygen transport. Arteriovenous shunting has been implicated as a cause of focal pockets of ischaemic synovium. This effect could be achieved in several ways, which have been reported independently. The obliteration of terminal vascular plexi ${ }^{2} 1617$ provides one possible cause of arteriovenous shunting. Microvascular damage such as this also leads to increased permeability and local oedema through impaired fluid resorption. Another ischaemia promoting rheumatoid characteristic is that of irregularly distributed synovial vasculitis. ${ }^{18}$ Microvessel plugging by inflammatory cells also serves to reroute blood from the peripheral capillary beds. This is associated to a varying degree with microthrombi ${ }^{19}$ and extravascular aggregates of platelets. ${ }^{20}$

Interestingly, the digital arteries in rheumatoid arthritis have also been found to show occlusive obliteration in the proximity of joint effusions. ${ }^{2122}$ It is thought, however, that the capillary and venular changes leading to stagnation of synovial blood flow ${ }^{23}$ (at least focally) are the most important factors that convincingly implicate disseminated microangiopathy in rheumatoid pathogenesis. ${ }^{24}$

These observations, which are for the most part subjective, go some way towards explaining synovial fluid hypoxia. Until recently, however, there has been a paucity of quantitative (morphometric) information on the functional 
adequacy of the synovial vasculature. In the normal joint the synovial membrane is only a few cells thick, but incorporated into this is a dense vascular plexus. The important vascular parameters which govern the efficacy of the oxygen delivery system are capillary number density, capillary spatial distribution, and blood flow. Morphometry of tissue sections of normal human knee synovium has supplied data on the first two of these features. ${ }^{2526}$ From these data the functionally optimal range of vascular parameters for the synovium can be extrapolated. The normal data from human knees correlate well with the results of similar morphometric analysis of rabbit knee synovium. ${ }^{27}$ When the same criteria were used to evaluate chronically inflamed rheumatoid synovia a significant reduction in vascularity was shown in the functionally important superficial region of the synovium. ${ }^{25}{ }^{28}$ Capillary number density in rheumatoid synovium is significantly reduced to about one third of normal, reflecting not only an increased spatial distribution of the microvasculature but also a grossly thickened synovial lining. The average capillary distance from the joint cavity is significantly increased from 32.5 $\mu \mathrm{m}$ to $93.3 \mu \mathrm{m}$. This apparent 'burial' of the vasculature is due to the thickening of synovial lining, which apparently proceeds at a greater pace than angiogenesis

Why does the inflamed rheumatoid joint become hypoxic?

There are two explanations which individually could provide the answer to why inflamed joints are hypoxic-namely, the increased metabolic demand of the inflamed synovium, and inadequate oxygen delivery through poor perfusion of the inflamed joint. In fact, both are characteristic of the inflamed joint.

\section{SYNOVIAL METABOLISM}

The oxygen consumption of the rheumatoid synovial membrane per gram of excised tissue is about 20 times that of normal. This work by Dingle and Page-Thomas ${ }^{29} 30$ and by Roberts $e t$ $a l^{31}$ also showed that the activity of the glycolytic (Embden-Meyerhof) pathway for ATP production was markedly greater in rheumatoid synovium that in normal synovium. The raised metabolic rate of the rheumatoid synovium concomitantly raises the demand for ATP. The intracellular production of this molecule can be achieved by either the aerobic or anaerobic oxidation of glucose via the tricarboxylic acid cycle or the glycolytic pathway respectively. The oxygen dependent tricarboxylic acid cycle is a much more efficient producer of ATP than the anaerobic system and so is generally favoured in normoxic tissues. The rheumatoid synovium favours the anaerobic glycolytic pathway, which indicates its hypoxic nature. In support of this, Henderson et al have shown that synovial lining cells in rheumatoid arthritis contain significantly more glyceraldehyde-3phosphate and lactate dehydrogenase activity than those of normal tissue. ${ }^{32}$ These are the major enzymes of the glycolytic pathway. Their increase is more reasonably explained by a response to tissue hypoxia than by raised metabolic activity as mitochondrial oxidation in the synovium is not similarly enhanced. ${ }^{33}$

The terminal end product of the anaerobic oxidation of glucose is lactate. The ratio of lactate to glucose,$^{10}$ therefore, should give an indication of oxygen status in the synovium. This is indeed the case, as Goetzl et al have shown that lowered glucose and raised lactate concentrations correlate well with falls in $\mathrm{PO}_{2}$ and $\mathrm{pH}^{6}$

\section{SYNOVIAL PERFUSION}

There have been numerous attempts to measure blood flow directly by a variety of methods. Unfortunately, none has succeeded in measuring the absolute flow per unit volume of synovium.

To meet the metabolic demands of the inflamed synovium a marked increase in perfusion would be required. Although some studies have reported some increase in perfusion, ${ }^{3}{ }^{35}$ the extent is probably less than adequate. In any event, the validity of these studies is in question because of methodological problems. ${ }^{28} 36$ Any such study must take into account the possibility of arteriovenous shunting giving the impression of perfusion but resulting in ischaemic, non-perfused synovial pockets. Falchuk et al concluded that synovial perfusion was increased in rheumatoid arthritis but overlooked the possibility of arteriovenous shunting in assuming that the measured synovial fluid $\mathrm{Po}_{2}$ equalled that of the venous blood draining the joint. ${ }^{3}$ Other studies ${ }^{7}$ using clearance of ${ }^{123} \mathrm{I}$ and tritiated water ${ }^{37}$ indicate that joint perfusion in chronic synovitis is markedly reduced. Whereas intra-articular temperature in acutely inflamed joints is higher than that found in normal joints, joint temperature in severe proliferative chronic arthritis may be lower than normal, ${ }^{7}$ essentially implying that blood flow in these most affected joints is insufficient to provide adequate perfusion.

\section{Acute exacerbation of chronic hypoxia}

A distinguishing property of the diarthrodial joint is its ability to move. The inflamed joint of a mobile patient is unavoidably subjected to movement. This situation we believe has profound significance in joint pathogenesis through the effects of ischaemia-reperfusion injury. ${ }^{38}$

The environment for ischaemia and reperfusion in rheumatoid synovitis is created by the unique topography of the component parts of a joint, which predisposes the synovium to pressure induced fluctuations in blood supply. The synovium is the innermost confine of the joint space and its fluid. This movable and compressible stroma is backed by the more rigid confines of the musculature and ligaments. It might be expected, therefore, that increasing the volume of fluid effusion concomitantly with synovial centripetal thickening (cf rheumatoid arthritis) generates a pressurised system. This is indeed the case. We have confirmed that the resting intra-articular pressure in chronically 
inflamed joints is slightly above atmospheric pressure (+5-10 $\mathrm{mmHg}$ ) compared with that of normal joints which is subatmospheric ( -5 $\mathrm{mmHg}) .{ }^{39}$ When normal joints (knee) are exercised the pressure falls further, whereas in chronically inflamed joints intra-articular pressure rises, sometimes as high as $300 \mathrm{mmHg}$ and always above $40 \mathrm{mmHg}$. The capillary perfusion pressure in inflammation is of the order of $20-30 \mathrm{mmHg}$. It is therefore suggested that in chronically inflamed joints the intra-articular pressure rises during exercise above a critical level sufficient to occlude parts of the capillary bed, thus inducing acute ischaemia in an already hypoxic environment. Recent independent observations have supported the hypothesis of ischaemia induced by intra-articular pressure. James et al have shown in rheumatoid patients with knee effusions that increases in intra-articular pressure in the range encountered during daily activity can compromise blood flow. ${ }^{5}$ This effect is associated with increased synovial fluid lactate, raised $\mathrm{PCO}_{2}$, and decreased $\mathrm{pH}$. McDonald and Levick have shown in rabbit knees that intra-articular pressures as low as $19 \mathrm{mmHg}$ cause synovial capillaries to assume a more flattened, elliptical profile. $^{40}$

In mobile patients, who may be subjecting their joints to pressure induced ischaemia, subsequent rest allows reperfusion of blood and reoxygenation of the synovium, albeit to an inadequate degree. This eventuality, we believe, has pathological repercussions consequent on the generation of reactive oxygen metabolites which accompanies postischaemic reperfusion. The evidence for this hypothesis has recently been summarised. ${ }^{39}$

\section{BIOCHEMICAL CONSEQUENCES OF SYNOVIAL} HYPOXIA

In normoxic synovium energy is derived from oxidative metabolism of fatty acids and glucose. The contribution of anaerobic glycolysis is small, and glycogen stores are maintained. In the hypoxic synovium the tricarboxylic acid cycle is substituted by anaerobic glycolysis ${ }^{32}$ using glycogen. This metabolic shift induces synovial lactic acidosis. When the pH becomes sufficiently low anaerobic glycolysis is also inhibited, resulting in chronic ATP depletion. ${ }^{41} 42$ In this environment several important biochemical events take place which have major significance in the pathology of synovitis. Calcium imbalance is arguably the most influential of these events. Intracellular homeostasis, with respect to $\mathrm{Ca}^{2+}$, is dependent upon energy in the form of ATP. When ATP availability is compromised, as in the hypoxic synovium, cytosolic $\mathrm{Ca}^{2+}$ levels rise. Mitochondria are avid accumulators of $\mathrm{Ca}^{2+}$, and when overloaded with $\mathrm{Ca}^{2+}$ their function is impaired, ${ }^{43}$ resulting in the further depletion of ATP levels and the maintenance of a calcium influx. ${ }^{44}$ Many important cellular functions and control mechanisms are dependent on $\mathrm{Ca}^{2+}$. The consequences of hypoxia derived $\mathrm{Ca}^{2+}$ imbalance must be considered as possible contributing factors in the pathogenesis of rheumatoid arthritis. The failure of cellular phosphorylation mechanisms also leads to accumulation of adenosine (a putative angiogenic factor) and of its breakdown products, including hypoxanthine and xanthine, which are the substrates for the xanthine oxidase enzyme system (see below). The outcome of these events in the hypoxic synovium confers the facility for the inappropriate generation of reactive oxygen metabolites upon reperfusion of blood. There is much evidence to show that postischaemic reperfusion of the synovium evokes the generation of reactive oxygen metabolites despite the underlying hypoxic environment which is not conducive to most conventional radical generating mechanisms. ${ }^{45}$ One proposed mechanism which can achieve this is dependent on the enzyme xanthine oxidase ${ }^{4647}$ which is present in the synovium. ${ }^{48}$ The non-pathological dehydrogenase form of this enzyme oxidises hypoxanthine and xanthine to uric acid using $\mathrm{NAD}^{+}$as an electron acceptor. Under ischaemic conditions, however, this enzyme can be converted to an $\mathrm{NAD}^{+}$independent form which catalyses the same reaction using molecular oxygen as an electron acceptor, resulting in superoxide anion generation. ${ }^{46}$ The inappropriate production of superoxide in a biological system can have catastrophic repercussions, particularly when the system facilitates the redox environment required for consequent hydroxyl radical $\left({ }^{\circ} \mathrm{OH}\right)$ formation. The synovium is such a system enabling the spontaneous or enzymatic conversion of superoxide to hydrogen peroxide, which can then fuel a Fenton-type reaction catalysed by decompartmentalised iron, ${ }^{49}$ forming the cytotoxic ${ }^{\circ} \mathrm{OH}$ species thus:

$$
\mathrm{H}_{2} \mathrm{O}_{2}+\mathrm{Fe}^{2+} \rightarrow \cdot \mathrm{OH}+\mathrm{OH}+\mathrm{Fe}^{3+}
$$

BIOLOGICAL CONSEQUENCES OF REACTIVE OXYGEN METABOLITES

Biochemical analysis of synovial fluid shows the effects of radical damage to endogenous biomolecules in rheumatoid arthritis. For example, the end products of lipid peroxidation, ${ }^{50}$ fluorescent IgG, ${ }^{51-53}$ and inactivated $\alpha_{1}$ proteinase inhibitor $^{54}$ are indicative of radical attack and are characteristic findings in rheumatoid synovial fluid. Interestingly, Garret et al have recently shown that superoxide anion stimulates osteoclast bone resorption in vitro and in vivo. ${ }^{55}$ Many other examples of oxidative damage to the joint have been reported and are reviewed elsewhere. ${ }^{56}$ Apart from these damaging or cytotoxic properties of free radicals, they also have the ability to interfere subtly with finely controlled cellular mechanisms. One example of this occurs in the control of vascular tone by vasoactive substances.

OTHER BIOLOGICAL CONSEQUENCES OF HYPOXIA TRANSFORMED BIOCHEMISTRY

An extensive range of publications shows that hypoxia has very profound effects in biological systems. In this review we have selected for discussion some of the more pertinent effects which we believe have implications in rheuma- 
toid arthritis. Our examples are confined for the most part to the endothelial cell. All other cell types, however, show profound changes when subjected to hypoxia.

\section{Vasoactivity}

An obvious vascular response to tissue ischaemia would be to lower its resistance to blood flow by vascular relaxation. This has been shown to be the case in some systems where hypoxia induced release of prostacyclin (prostaglandin $I_{2}$ ) is sufficient to elicit endothelium dependent dilatation. ${ }^{57}$ Pohl and Busse have also shown that hypoxia stimulates the release of an endothelium derived relaxing factor from rabbit femoral artery and aorta. ${ }^{58}$ In the pulmonary circulation, however, it has been known for many years that hypoxia causes vascular constriction. ${ }^{59}$ The benefit of this is in rerouting most of the blood flow to the best oxygenated parts of the lung. Other pulmonary studies have shown that hypoxia blocks endothelium derived relaxing factor production. ${ }^{6061}$ and induces the release of a constricting factor ${ }^{62}$ from the endothelium. These conflicting reports highlight the heterogeneity of endothelial cell responses to the same stimulus in different situations and environments, allowing the possibility of an apparently appropriate response eventually to become pathological.

Hypoxia has other quite pronounced effects on endothelial cells, for example in von Willebrand factor release (discussed later), reducing plasminogen activator activity, ${ }^{63}$ and increasing superoxide dismutase activity. ${ }^{64}$ The endothelium also produces other very powerful vasoactive substances, which may be mediated by hypoxia. These include platelet activating factor $^{65}$ and the highly potent vasoconstrictor endothelin. ${ }^{66}$ In addition, endothelial cells have a pivotal role in the initiation, regulation, and maintenance of the inflammatory process ${ }^{67}$ through the induction of changes in their interactions with blood constituents. These factors, when considered in parallel with the susceptibility to perturbation by hypoxia of the endothelial cell, confer its prominent role in the pathogenesis of ischaemic states.

The activity of endothelium derived relaxing factor has been ascribed to the nitrogen centred radical nitric oxide (NO), ${ }^{68}$ which is synthesised in endothelial cells by a $\mathrm{Ca}^{2+}$ dependent enzymatic conversion of $\mathrm{L}$-arginine. Nitric oxide can interact with superoxide to produce the highly cytotoxic hydroxyl radical through peroxynitrite. ${ }^{69}$ In vitro this interaction abrogates the endothelium derived relaxing factor activity of NO as shown by the ability of superoxide dismutase to enhance and prolong the relaxant effect of NO. ${ }^{71}$ Vascular tone is controlled by the opposing actions of relaxing and contracting factors released from the endothelium in response to neurogenic stimuli or platelet products. Superoxide has itself been implicated as an endothelium derived contracting factor ${ }^{72 / 3}$ along with endothelin. It is feasible, therefore, that an effect of hypoxia in the synovium is paradoxical vasoconstriction, ${ }^{74}$ effectively worsening the situation.
Leucocyte chemotaxis and adhesion

The initiating factors of inflammatory cell infiltration are adherence to endothelium and chemotaxis. The activation pathways and mechanisms of initiation for adhesion are reviewed elsewhere. ${ }^{75}$ Synovial inflammatory cell infiltration is a major characteristic of rheumatoid arthritis, as is the expression of membrane associated adhesion molecules. The contribution of hypoxia to this situation may have considerable significance, particularly where oxygen free radicals are a consequence. Several reports show that superoxide, hydrogen peroxide, or both, can generate a chemoattractant for neutrophils from extracellular fluid. ${ }^{76} 77$ The identity of the neutrophil chemotactic factor(s) generated in ischaemia is unknown. Possible candidates are cyclooxygenase and lipoxygenase metabolites of arachidonic acid, such as 12-hydroxyeicosatetraenoic acid, which is found to be raised in hypoxic states ${ }^{78}$ and is a neutrophil chemoattractant. ${ }^{79}$ In support of this, Farber et al have shown that cultured endothelial cells can respond to hypoxia by producing a neutrophil chemoattractant, which is suppressible by lipoxygenase inhibitors. ${ }^{80}$

The adhesion component of leucocyte infiltration can be facilitated by oxygen radicals ${ }^{81}$ and by ischaemia alone. ${ }^{82} 83$ Interestingly, the adhesion of neutrophils to ischaemic arterial vasculature is associated with a loss of endothelium dependent vasorelaxant activity. ${ }^{83}$

\section{Microvascular barrier function}

In any inflammatory condition the manifestation of the inflammatory response is controlled by the permeability of the microvascular blood/ tissue barrier. Increased transvascular exchange of macromolecules, emigration of leucocytes, and oedema formation are indicative of modified barrier function and are characteristic of synovial inflammation. The dynamics of barrier function, particularly solute exchange, are modulated physiologically by a complex assortment of mediators. During hypoxia, however, homeostasis is disrupted by, as yet, poorly understood mechanisms involving mediators of altered barrier function, such as platelet activating factor, complement, leukotrienes, and prostaglandins. The mechanism for increased permeability, when associated with interendothelial gap formation, is thought to involve changes in the actin cytoskeleton of the endothelial cell. ${ }^{84}$ These changes can be elicited by calcium imbalance as actin binding proteins which regulate the endothelial cytoskeleton are calcium dependent. ${ }^{85}$ Increased permeability during ischaemia or hypoxia has been reported from many vascular and culture systems-for example, heart, ${ }^{86-88}$ lung, ${ }^{89} 90$ brain, ${ }^{91}$ and cultured bovine endothelium. ${ }^{92}$

In addition to the effects of hypoxia alone, rheumatoid synovial microvascular permeability can be altered by the membrane damaging effects of oxygen free radicals. ${ }^{93} 94$ 
factor VIII related antigen, is a large adhesive glycoprotein which is synthesised in endothelial cells and megakaryocytes and plays an important part in the adhesion of platelets to damaged vessel walls. Small subunits of von Willebrand factor are released constitutively by endothelial cells, accounting for normal circulating plasma concentrations. Larger multimers of von Willebrand factor are stored in specific organelles called Weibel-Palade bodies within endothelial cells. Interestingly, these bodies are common in the synovium and have been implicated as a marker of angiogenesis in rheumatoid arthritis. ${ }^{95}$ Various physiological stimuli can induce acute release of these multimers from the WeibelPalade bodies in vitro. Raised concentrations of plasma von Willebrand factor have been found in various disease states, including rheumatoid arthritis. ${ }^{96} 97$ This phenomenon has been taken to indicate vascular damage. ${ }^{98}$ Significantly, there is evidence that $\mathrm{Ca}^{2+}$ influx mediates the release of von Willebrand factor from endothelial cells. ${ }^{99} 100$ This has obvious bearing on the recent finding that simulated ischaemia (an inducer of $\mathrm{Ca}^{2+}$ influx) in cultured endothelial cells causes membrane changes, Weibel-Palade body exocytosis, and an associated release of von Willebrand factor, which is detectable by enzyme linked immunosorbent assay (ELISA). ${ }^{101}$ The probability that this mechanism operates in the rheumatoid synovium is emphasised by the immunohistochemical demonstration of a patchy von Willebrand factor distribution in the most hypoxic regions, suggesting von Willebrand factor release. ${ }^{101}$ This may provide an explanation for the aggregates of platelets in the synovium ${ }^{20}$ and for microthrombi which can be caused by von Willebrand factor release from Weibel-Palade bodies. ${ }^{102}$ Platelet aggregation elicits several notable endothelial cell responses, including endothelium derived relaxing factor release ${ }^{103}$ and angiogenesis. In the context of the former response, Ashmore et al have shown that adenine nucleotides released from aggregating platelets stimulate a rise in intracellular $\mathrm{Ca}^{2+} .104$ The effects of platelet induced $\mathrm{Ca}^{2+}$ increase are not necessarily limited to endothelium derived relaxing factor release but may also represent a common mechanism for the release of other endothelium derived mediators, such as von Willebrand factor, plasminogen activator, prostacyclin, and endothelin.

\section{Platelet activating factor}

Platelet activating factor is the name given to a family of structurally related acetylated phosphoglycerides, or lipid autacoids. It is well known to be a potentially critical mediator in diverse pathological processes. In this respect many of the most important physiological actions of platelet activating factor are platelet independent. Platelet activating factor is synthesised by a variety of cell types after appropriate stimulation. ${ }^{105}$ An increasing volume of evidence indicates that its synthesis or release can be stimulated in ischaemia. ${ }^{106-108}$ Furthermore, it has been suggested that platelet activating factor release accounts for some of the damage seen in ischaemic conditions as treatment with platelet activating factor antagonists affords protection against such damage. ${ }^{109110}$ Platelet activating factor has been implicated in many disorders through various aspects of its multiple biological activities. In the ischaemic synovium of rheumatoid arthritis its most important effects are probably as an accessory factor to increased vascular permeability ${ }^{111} 112$ or in the amplification cycle of endothelial cell injury. ${ }^{105}$ Hence, platelet activating factor is a potential participant in the still evolving cycle of events which generate persistent synovial inflammation.

\section{Angiotensin converting enzyme}

Endothelial cells contain angiotensin converting enzyme, which converts vasoinactive angioten$\sin$ I to the vasoconstrictor angiotensin II and inactivates bradykinin. ${ }^{113} 114 \mathrm{It}$ is of significance to this review that angiotensin II stimulates endothelial cells to synthesise platelet activating factor. ${ }^{115}$ In a variety of vascular systems both increased $^{116} 117$ and decreased ${ }^{118}$ angiotensin converting enzyme activity have been reported after exposure to hypoxia. This may reflect once more the heterogeneity of endothelial cell responses to hypoxia in various tissues. The finding that angiotensin converting enzyme activities are markedly increased in rheumatoid synovial fluid ${ }^{119}$ may indicate a direct effect of hypoxia or acute release due to ischaemic damage to synovial endothelial cells. The part played by angiotensin converting enzyme in rheumatoid arthritis warrants further investigation, inasmuch as high activity in synovial fluid would exacerbate ischaemia through the down-regulation of a vasodilator (bradykinin) concomitantly with the generation of the vasoconstricting peptide angiotensin II.

\section{Attempts of the joint to limit hypoxic damage} The immediate local response to tissue hypoxia is elicited by the vasculature, using vasoactive substances which serve to enhance perfusion. It is clear that the facility for this response is impaired in rheumatoid synovitis. A more long term strategy for the re-establishment of adequate perfusion is neovascularisation of hypoxic tissue. The facility for this, termed angiogenesis, most certainly exists in the rheumatoid synovium, to an extent which some believe to be pathological.

Under conditions of physiological stress, such as hypoxia, cell survival may become dependent on the expression of a specialised set of proteins, termed heat shock proteins. There is reason to believe that these proteins have an important protective role in the chronically hypoxic rheumatoid synovium.

\section{ANGIOGENESIS}

The formation and growth of new blood vessels is under rigid control, so much so that in health angiogenesis only occurs in wound healing and during endometrial regeneration. Functional aberrations of the physiological regulation of new capillary growth such as seen in ischaemia and reperfusion are implicated in the patho- 
genesis (if not aetiology) of many neoplastic and non-neoplastic diseases.

The neovascularisation of a wound progresses, logically, towards the centre where hypoxic macrophages are stimulated to produce angiogenic factors. ${ }^{120}$ This is fundamental evidence which supports the hypothesis that exposure to hypoxia causes the blood vascular system to adapt its structure to allow greater amounts of blood to flow to the tissues at any given perfusion pressure gradient. Much more evidence in support of this has been reported pertaining to pathological hypoxia. Angiogenesis is a well documented physiological response to myocardial infarction. ${ }^{121}$ In response to hypoxia the infarcted tissue is repaired by neovascularisation emanating from the surrounding myocardium. It has been suggested that this is achieved by a low molecular weight angiogenesis factor that can be extracted from human myocardial infarcts. ${ }^{122}$ Hypoxia driven neovascularisation in the eye is said to be one of the most common causes of blindness, for example as in diabetic retinopathy, ${ }^{123}$ neovascular glaucoma, ${ }^{124}$ and the retinopathy of prematurity. ${ }^{125}$ Pertinent to the latter disorder, a 15-lipoxygenase metabolite of arachidonic acid 15hydroxyeicosatetraenoic acid, which is proangiogenic, has been shown to be markedly raised in hypoxic neonatal vasculature. ${ }^{125}$

The persistent synovitis characteristic of rheumatoid arthritis equates with persistent, though perhaps not fully effective, angiogenesis. The resulting fibroproliferative, inflammatory pannus invades and elicits the destruction of articular cartilage, leading to joint deformation and loss of function. Clearly the rheumatoid joint is a victim of angiogenesis, although morphometry suggests that this does not keep pace with synovial proliferation. ${ }^{25}$ This situation, as has been discussed earlier, promotes hypoxia in the peripheral region of the synovium, which is rich in macrophages. The evidence that rheumatoid synovial tissue macrophages $^{126}$ and hypoxic macrophages ${ }^{120}$ release a substance capable of inducing angiogenesis invites the hypothesis that hypoxia drives synovial angiogenesis. The macrophage derived angiogenic factor is thought to be tumour necrosis factor $\alpha$. Tumour necrosis factor $\alpha$ has been localised histochemically to the synovial lining cells in rheumatoid arthritis, but no prominent staining is seen in osteoarthritis noninflammatory samples. ${ }^{127}$ The accumulation of adenosine is a feature of hypoxic cells. Adensone ${ }^{128}$ and other hypoxia induced nucleotide degradation products ${ }^{129}$ have shown proangiogenic activities. Hyaluronan, a constituent of synovial fluid which can be oxidatively degraded, has both angiogenic and antiangiogenic capabilities. Its degradation products are proangiogenic, ${ }^{130}$ whereas high molecular mass hyaluronan has inhibitory effects on endothelial cell proliferation. ${ }^{131}$ In addition to the list of possible angiogenic factors which coexist in rheumatoid arthritis, the synovium has been shown to contain a low molecular weight angiogenesis factor, ${ }^{132} 133$ similar if not identi$\mathrm{cal}$ to that extractable from tumours ${ }^{134}$ and myocardial infarcts. ${ }^{122}$
HEAT SHOCK PROTEINS

A more suitable term to describe these ubiquitous intracellular proteins is 'stress proteins'. This is because the expression of these proteins can be effected by a heterogeneous assortment of stressors other than heat. ${ }^{135}$ Stress protein mRNAs are actively transcribed on the activation of a number of specific genes which are normally dormant or only partially active. Their function is still being researched, but it is thought that they confer protection to stressed cells in a variety of ways. The $32 \mathrm{kDa}$ stress protein, for example, is induced by hydrogen peroxide and results in the efficient scavenging of reactive oxygen metabolites. ${ }^{136}$ Repeated or continuous stressing of cells producing specific stress proteins results in tolerance to the initial stressor and to certain others simultaneously. Of relevance to this discussion, is the recognition that both hypoxia ${ }^{137} 138$ and reactive oxygen metabolites ${ }^{138} 139$ evoke stress protein responses. The heat shock protein response in arthritis has been reviewed recently by Winrow et $a l,{ }^{140}$ who describe the histochemical localisation of certain heat shock proteins to the inflamed rheumatoid synovium and speculate on the function of these in limiting hypoxicreperfusion injury.

The heterogeneity of cellular responses to hypoxia has already been alluded to. Similarly, the viability and proliferation parameters of different cell types vary significantly in reduced $\mathrm{Po}_{2}$. It is not unreasonable to suppose that heat shock proteins play a part in this heterogeneity owing to their differential cellular expression in response to a particular stressor. It is an intriguing possibility that the specific cell populations comprising the cellular milieu of rheumatoid synovium are regulated by the combination of hypoxic stress and heat shock protein response.

\section{Comment}

Variable tissue hypoxia is a feature of chronic synovitis. The biological consequences of this are diverse, complex, and profound. We believe that researchers within rheumatology take little note of this when conducting ex vivo experiments. Is it reasonable to study a cell's behaviour or cell to cell interactions in a culturing environment $\left(\mathrm{Po}_{2} \sim 152 \mathrm{mmHg}, \mathrm{PCO}_{2} \sim 38 \mathrm{mmHg}\right.$, and $\mathrm{pH} \sim 7 \cdot 4)$ and draw conclusions thought relevant to chronic synovitis when those cells exist in vivo in an environment that is profoundly different? The answer is clearly no.

CRS is supported by a project grant from the Arthritis and Rheumatism Council (ARC). DRB has an endowed ARC professorship held by the London Hospital Medical College (LHMC).

We are grateful for discussions within the LHMC Inflammation Group that have provided the incentive for these 'deliberations'. Specific studies referred to based at the LHMC 'deliberations'. Specific studies referred to based at the LHMC have been supported by the ARC, Dista Pharmaceuticals
the British Technology Group, and Pharmacia (Sweden).

1 Lund-Olesen K. Oxygen tension in synovial fluids. Arthritis Rheum 1970; 13: 769-6.

2 Treuhaft P S, McCarty D J. Synovial fluid pH, lactate, oxygen and carbon dioxide partial pressures in various joint diseases. Arthritis Rheum 1971; 14: 475-84.

3 Falchuk K H, Goetzl E J, Kulka J P. Respiratory gases of synovial fluids. An approach to synovial tissue circulatory- 
metabolic imbalance in rheumatoid arthritis. Am $\mathcal{J}$ Med 1970; 49: 223-31.

4 Geborek P, Saxne T, Pettersson H, Wollheim F A. Synovial fluid acidosis correlates with radiological joint destruction in rheumatc

5 James M J, Cleland L G, Rofe A M, Leslie A L. Intraarticular pressure and the relationship between synovial articular pressure and the relationship between synovial
perfusion and metabolic demand. 7 R heumatol 1990; 17: perfusion

6 Goetzl E J, Fa!chuk K H, Zeiger L S, et al. A physiological approach to the assessment of disease activity in rheumaoid arthritis. F Clin Invest 1971; 50: 1167-80.

7 Wallis W J, Simkin P A, Nelp W B. Low synovial clearance of iodide provides evidence of hypoperfusion in chronic rheumatoid synovitis. Arthritis Rheum 1985; 28: 1096-104.

8 Jebens $\mathrm{E} \mathrm{H}$, Monk-Jones $\mathrm{M} \mathrm{E}$. On the viscosity and $\mathrm{pH}$ of synovial fluid and the $\mathrm{pH}$ of blood. 7 Bone Foint Surg $[\mathrm{Br}]$ 1959; 41: 388-400.

9 Richman A I, Su E Y, Ho G Jr. Reciprocal relationship of synovial fluid volume and oxvgen tension. Arthritis Rheum 1981; 24: 701-5.

10 Ropes M, Bauer W. Synovial fluid changes in joint disease. Boston: Harvard University Press, 1953.

11 McCarty D. Selected aspects of synovial fluid physiologv. Arthritis Rheum 1974; 17: 289-.96.

12 Unsworth J, Outhwaite J, Blake D R, Morris C J, Freeman J. Dynamic studies of the relationship between intraarticular pressure, synovial fluid oxygen tension, and lipid peroxidation in the inflamed knee: an example of reperfusion injury. Ann Clin Biochem 1988; 25: 8s-11s.

13 Matsubara T, Velvart M, Odermatt B F, Spycher M A, Rüttner J R, Fehr K. The thickening of basement membrane in synovial capillaries in rheumatoid arthritis. Rheumatol Int 1983; 3: 57-64.

14 Elemer G, Kerenyi T, Jellinek H. Scanning (SEM) and transmission (TEM) electron-microscopic studies on postischaemic endothelial lesions following recirculation. Atherosclerosis 1976; 24: 219-32.

15 James W R, Thomas A J. The effect of hypoxia on the heart and pulmonary arterioles of mice. Cardiovasc Res 1968; 2 : $278-83$.

16 Kulka J P. Microcirculatory impairment as a factor in inflammatory tissue damage. Ann NY Acad Sci 1964; 116: $1018-44$

17 Bierther M. Electron microscopy study of changes in synovial blood vessels during rheumatoid arthritis. Reumatizam 1973; 20: 53-61.

18 Goldie I. The synovial microvascular derangement in rheumatoid arthritis and osteoarthritis. Acta Orthop Scand 1970; 40: 751-64

19 Kulka J P. Vascular derangement in rheumatoid arthritis. In: Hill A, ed. Modern trends in rheumatology. London: Butterworth, 1966: 49-69.

20 Palmer D G, Hogg N, Revell P A. Lymphocytes, polymorphonuclear leukocytes, macrophages and platelets in morphonuclear leukocytes, macrophages and platelets in movium involved by reumatoid 1986; 18: 431-7.

21 Virtama P. Changes of the digital arteries in rheumatoid arthritis: a study with the aid of post mortem brachial arteriography. Acta Rheumatologica Scandinavica 1959; 5: $304-13$

22 Rao S V, Misra R C, Chugh S K, Ahuja P, Saha M M, Bhardway O P. Digital arteriopathy in rheumatoid arthritis. F Chronic Dis 1976; 29: 205-12.

23 Branemark P I, Lindstroem J, Johanson I, et al. Capillary structure and function in rheumatoid arthritis. A vita microscopic study of conjunctival and surgically exposed joint tissue. Acta Rheumatologica Scandinavica 1973; 9: 284-92.

24 Kulka J P. The pathogenesis of rheumatoid arthritis. $f$ Chronic Dis 1959; 10: 388-402.

25 Stevens C R, Revell P A, Blake D R, Levick J R. Synovial vascular morphometry suggests that a state of chronic vascular morphometry suggests that a state of chronic 28 (suppl 2):62.

26 Wilkinson L S, Edwards J C W. Microvascular distribution in normal human synovium. $\mathcal{F}$ Anat 1989; 167: 129-36.

27 Knight A D, Levick J R. The density and distribution of capillaries around a synovial cavity. Q f Exp Physiol 1983; 63: $629-44$

28 Levick J R. Hypoxia and acidosis in chronic inflammatory arthritis; relation to vascular supply and dynamic effusion pressure. I Rheumatol 1990; 17: 579-82.

29 Page-Thomas D P, Dingle J T M. In vitro studies of rheumatoid synovium. Preliminary metabolic comparison between synovial membrane and villi. Br $\mathcal{F}$ Exp Patho 1955; 36: 195

30 Dingle J T M, Page-Thomas D P. In vitro studies in human synovial membrane. A metabolic comparison of norma and rheumatoid disease. Br $\mathcal{F}$ Exp Pathol 1956; 37: and rhe

31 Roberts J E, McLees B D, Kerby G P. Pathways of glucose metabolism in rheumatoid and non-rheumatoid synovium. metabolism in rheumatoid and no

32 Henderson B, Bitensky L, Chayen J. Glycolytic activity in human synovial lining cells in rheumatoid arthritis. Ann Rheum Dis 1979; 38: 63-7.

33 Henderson B, Bitensky L, Chayen J. Mitochondrial oxidative activity in human rheumatoid synovial lining cells. Ann Rheum Dis 1978; 37: 548-57.

34 Nicholson J K, Buckingham M J, Sadler P J. High resolution ' $H$ NMR studies of vertebrate blood plasma. Biochem f 1983; 211: 605-15.
35 Dick W C St, Onge R A, Gillespie F C, et al. Derivation of knee joint synovial perfusion using the xenon $\left({ }^{133} \mathrm{Xe}\right)$ clearance technique. Ann Rheum Dis 1970; 29: 131-4.

36 Phelps P, Steele A D, McCarty D J. Significance of xenon133 clearance rate from canine and human joints. Arthritis Rheum 1972; 15: 360-70.

37 Simkin P A, Pizzorno J E. Synovial permeability in rheumatoid arthritis Arthritis Rheum 1979; 22: 689-96.

38 Woodruff T, Blake D R, Freeman J, Andrews F J, Salt P, Lunec $J$. Is chronic synovitis an example of reperfusion injury? Ann Rheum Dis 1986; 45: 608-11.

39 Blake D R, Merry P, Unsworth J, et al. Hypoxic-reperfusion injury in the inflamed human joint. Lancet 1989; i: 289-93.

40 McDonald J N, Levick J R. Pressure induced deformation of the interstitial route across synovium and its relation to hydraulic conductance. F Rheumatol 1990; 17: 341-8.

41 Jennings $R$ B, Reimer K A. Lethal myocardial ischaemic injury. Am F Pathol 1981; 102: 241-55.

42 Jennings R B, Reimer K A, Hill M A, Mayer S E. Total ischaemia in dogs hearts. I. A comparison of high energy phosphate production, utilisation and depletion and of adenine nucleotoide catabolism in total ischaemia in vitro. Circ Res 1981; 49: 892-900.

43 Nayler W G, Poole-Wilson P A, Williams A. Hypoxia and calcium. F Mol Cell Cardiol 1979; 11: 683-706.

44 Aw T Y, Andersson B S, Jones D P. Mitochondrial transmembrane ion distribution during anoxia. Am $f$ Physiol 1987; 252: C356-61.

45 Edwards S W, Hallet M B, Camphell A K. Oxygen radical production may be limited by oxygen concentration. Biochem 7 1984; 217: 851-4.

46 Roy R S, McCord J M. Superoxide and ischaemia conversion of xanthine dehydrogenase to xanthine oxidase. In: Greenwald R, Cohen G, eds. Oxy radicals and their scavenger systems. Vol 2. Cellular and molecular aspects. New York: Elsevier, 1983: 145-53.

47 McCord J M. Oxygen-derived radicals: a link between reperfusion injury and inflammation. Fed Proc 1987; 46: $2402-6$.

48 Allen R E, Outhwaite J, Morris C J, Blake D R. Xanthine oxidoreductase is present in human synovium. Ann Rheum Dis 1987; 46: 843-5.

49 Morris C J Blake D R, Wainwright A C, Steven M M Relationship between iron deposits and tissue damage in the synovium: an ultrastructural study. Ann Rheum $D$ is 1986; 45: 21-6.

50 Rowley D A, Gutteridge J M C, Blake D R, Farr M, Halliwell B. Lipid peroxidation in rheumatoid arthritis: thiobarbituric acid reactive material and catalytic iron salts in synovial fluid from rheumatoid patients. Clin S S i 1984; 66: 691-5.

51 Wickens D G, Norden A G, Lunec J, Dormandy T L. Fluorescence changes in human gamma-globulin induced by free radical activity. Biochim Biophys Acta 1983; 742: $607-16$.

52 Lunec J, Wakefield A, Brailsford S, Blake D R. Free radical altered IgG and its interaction with rheumatoid factor. In: altered IgG and its interaction with rheumatoid factor. In: Rice-Evans C, ed. Free radicals, cell dama
London: Richelieu Press, 1986: 241-61.

53 Lunec J, Blake D R, McCleary S J, Brailsford S, Bacon P A. Self perpetuating mechanisms of immunoglobulin G aggregation in rheumatoid inflammation. $f$ Clin Invest 1985; 76: 2084-90.

54 Wong P S, Travis J. Isolation and properties of oxidised alpha-1-proteinase inhibitor from human rheumatoid synovial fluid. Biochem Biophys Res Commun 1980; 96: 1449-54.

55 Garret I R, Boyce B F, Oreffo R O C, Bonewald L, Poser J, Mundy $G R$. Oxygen-derived free radicals stimulate osteoclast bone resorption in rodent bone in vitro and in vivo. 7 Clin Invest 1990; 85: 632-9.

56 Blake D R, Allen R E, Lunec J. Free radicals in biological systems-a review orientated to inflammatory processes. BrMed Bull 1987; 43: 371-85.

57 Busse R, Förstermann U, Matsuda H, Pohl U. The role of prostaglandins in the endothelium-mediated vasodilatory prostaglandins in the endothelium-mediated vasodilat

58 Pohl U, Busse R. Hypoxia stimulates release of endotheliumderived relaxant factor. Am $\mathcal{f}$ Physiol 1989; 256: H1595-600.

59 von Euler U S, Liliestrand G. Observations on the pulmonary arterial blood pressure in the cat. Acta Physiol Scand 1946; 112: 301-20.

60 Rodman D M, Yamaguchi T, Hasunuma K, O'Brien R, McMurty F. Effects of hypoxia on endotheliumdependent relaxation of rat pulmonary artery. $A m \mathcal{F}$ Physiol 1990; 258: L207-14

61 Warren J B, Maltby N H, MacCormack D, Barnes P J. Pulmonary endothelium-derived relaxing factor is im paired in hypoxia. Clin Sci 1989; 77: 671-6.

62 Peach M J, Singer H A, Loeb A L. Mechanisms of endothelium-dependent vascular smooth muscle relaxation. Biochem Pharmacol 1985; 34: 1867-74

63 Risberg B, Stenberg S. Modulation of tissue fibrinolysis from hypoxia and hyperoxia. Thromb Res 1985; 38: $129-36$.

64 Sjostrom K, Crapo J D. Structural and biochemical adaptive changes in rat lungs after exposure to hypoxia. Lab Inves 1983; 48: 68-79.

65 McIntyre M, Immerman G A, Satoh K, Prescott S M Cultured endothelial cells synthesize both platelet-activating factor and prostacyclin in response to histamine 
bradykinin and adenosine triphosphate. $\mathcal{F}$ Clin Invest 1985; 76: 271-80.

66 Yanagisawa M, Kurihara H, Kimura S, et al. A novel potent vasoconstrictor peptide produced by vascular endothelial cells. Nature 1988; 332: 411-5.

67 Petty R G, Pearson J D. The endothelial cell: the axis of vascular health and disease. $f R$ Coll Physicians Lond 1989; 23: 92-102.

68 Palmer R M J, Ferrige A G, Moncada S. Nitric oxide release accounts for the biological activity of endothelium derived relaxing factor. Nature 1987; 327: 524-6.

69 Beckman J S, Beckman T W, Chen J, Marshall P A Freeman B A. Apparent hydroxyl radical production by peroxynitrite: implications for endothelial injury from nitric oxide and superoxide. Proc Natl Acad Sci USA 1990; 87: 1620-4.

70 Gryglewski R J, Palmer R M J, Moncada S. Superoxide anions play a role in the breakdown of EDRF. Nature 1986; 320: 454-6.

71 Moncada S, Radomski M W, Palmer R M J. Endothelium derived relaxing factor: identification as nitric oxide and role in the control of vascular tone and platelet function. Biochem Pharmacol 1988; 37: 2495-501.

72 Vanhoutte $P$ M, Katusic Z S. Endothelium-derived contracting factor: endothelin and/or superoxide anion? Trends in Pharmacological Science 1988; 9: 229-30.

73 Katusik Z S, Vanhoutte P M. Superoxide anion is an endothelium-derived contracting factor. Am $\mathcal{J}$ Physiol 1989; 257: H33-7.

74 Vanhoutte $P$ M. The endothelium-modulator of vascula smooth-muscle tone. $N$ Engl f Med 1988; 319: 512-3.

75 Tonnesen M G. Neutrophil-endothelial cell interactions: mechanisms of neutrophil adherence to vascular endothelium. F Invest Dermatol 1989; 93: 53S-8S.

76 Petrone W F, English D K, Wong K, McCord J M. Free radicals and inflammation: superoxide-dependent activation of a neutrophil chemotactic factor in plasma. Proc Natl Acad Sci USA 1980; 77: 1159-63.

77 Perez H D, Weksler B B, Goldstein I M. Generation of a chemotactic lipid from arachidonic acid by exposure to a superoxide-generating system. Inflammation 1980; 4: superox.

78 Needleman P, Key S L, Isakson P C, Kulkarni S Relationship between oxygen tension, coronary vasoRelationship between oxygen tension, coronary vasodilation and prostaglandin biosynthesis in the

79 Turner S R, Tainer J A, Lynn W S. Biogenesis of chemotactic molecules of arachidonate lipoxygenase system of platelets. Nature 1975; 257: 680-1.

80 Farber $H W$, Center D M, Rounds S. Effect of ambien oxygen on cultured endothelial cells from different vascular beds. Am f Physiol 1987; 253: H875-83.

81 Suzuki $M$, Inauen $W$, Kvietys $P$, et al. Superoxide mediates reperfusion-induced leukocyte-endothelial cell interactions. Am $\mathcal{F}$ Physiol 1989; 257: H1740-5.

82 Mullane F M, Pinto A. Endothelium, arachidonic acid and coronary vascular tone. Fcd Proc 1987; 46: 54-62.

83 Grossman H J, Zambetis $M$. Leucocyte-induced endothelium-dependent vasodilatation and post-ischaemic vasospasm in the isolated rat superior mesenteric artery. $\mathrm{Br} f$ Exp Pathol 1989; 70: 515-23.

84 Shasby M, Lind S E, Shasby S S, Goldsmith J C, Hunninghake $G W$. Reversible oxidant-induced increase in albumen transfer across cultured endothelium: alterain ans in cell shape and calcium homeostatis. Blood 1985;
tions tions in 605 .

85 Hinshaw D B, Armstrong B C, Burger J M, Beals T F, Hyslop P A. ATP and microfilaments in cellular oxidan injury. Am f Pathol 1988; 132: 479-88.

86 Ward B J, Firth J A. Effect of hypoxia on endothelia morphology and interendothelial junctions in the isolated perfused rat heart. F Moll Cell Cardiol 1989; 21: 1337-47.

87 Meneely G R. The capillary factor in myocardial infarction. Am f Cardiol 1974; 34: 581-7.

88 Armiger C, Gavin J B. Changes in the microvasculature of ischaemic and infarcted myocardium. Lab Invest 1975; 33: ischaem.

89 Lockhart A, Saiag B. Altitude and the human pulmonary circulation. Clin Sci 1981; 60: 599-605.

90 Kinasewitz G, Groome L, Marshall R, Leslie W, Diana H. Effect of hypoxia on permeability of pulmonary endothelium of canine visceral pleura. $\mathcal{f}$ Appl Physiol 1986; 61: lium of

91 Oleson S-P. Rapid increase in blood-brain barrier permeability during severe hypoxia and metabolic inhibition. Brain Res 1986; 368: $24-9$.

92 Ogawa S, Gerlach H, Esposito C, Pasagian-Macaulay A, Brett J, Stern J. Hypoxia modulates the barrier and coagulant function of cultured bovine endothelium. Increased monolayer permeability and induction of procoagulant properties. F Clin Invest 1990; 85: 1090-8.

93 Del Maestro R F, Björk J, Arfors K-E. Increase in microvascular permeability induced by enzymatically generated free radicals. II. Role of superoxide anion radical, hydrogen peroxide, and hydroxyl radical. Micro-
vasc Res 1981; 22: 255-70.

94 Ley K, Arfors K-E. Changes in microvascular permeability by intravascular generation of oxygen-derived free radicals. Microvasc Res 1982; 24: 25-33.

95 Kumar P, Erroi A, Sattar A, Kumar S. Weibel-Palade bodies as a marker for neovascularization induced by tumor and rheumatoid angiogenesis factors. Cancer Res

96 Pottinger B E, Read R C, Paleolog E M, Higgins P G,
Pearson J D. von Willebrand factor is an acute phase reactant in man. Thromb Res 1989; 53: 387-94.

97 Woolf A D, Wakerley G, Wallington T B, Scott D G I Dieppe $\mathrm{P}$ A. Factor VIII related antigen in the assessment of vasculitis. Ann Rheum Dis 1987; 46: 441-7.

98 Greaves M, Pickering C, Knight G, Boulton A J M, Ball J Preston F E. Changes in the factor VIII complex in diabetic ketoacidosis: evidence of endothelial damage? diabetic ketoacidosis: evidence
Diabetologica 1987; 30: 160-5.

99 Loesberg C, Gonsalves M D, Zandbergen J, et al. The effect of calcium on the secretion of factor VIII-related antigen by cultured human endothelial cells. Biochim Biophys Acta 1983; 763: 160-8.

100 Hamilton K K, Sims P J. Changes in cytosolic $\mathrm{Ca}^{2}$ associated with von Willebrand factor release in human endothelial cells exposed to histamine. $\mathcal{f}$ Clin Invest 1987 79: $600-8$.

101 Stevens C R, Allen R E, Sahinoglu T, Blake D R. Mechanisms of increased factor VIII-related antigen release in ischaemia related to observations in rheumatoid arthritis. Br $\mathcal{F}$ Rheumatol 1990; 29 (suppl): 12.

102 Sporn L A, Rubin P, Marder V J, Wagner D D. Irradiation induces release of von Willebrand protein from endothelial cells in culture. Blood 1984; 64: 567-70.

103 Cohen R A, Shepherd J T, Vanhoutte P M. Inhibitory role of the endothelium in the response of isolated coronary arteries to platelets. Science 1983; 221: 273-4.

104 Ashmore R C, O'Brien R F, Stelzner T J, et al. Aggregating platelets increase intracellular calcium in endothelial cells through release of adenine nucleotides. Biochem Biophys Res Commun 1990; 166: 909-15

105 Braquet P, Touqui L, Shen T S, Vargaftig B B. Perspective in platelet-activating factor research. Pharmacol Rev 1987, 39: $97-145$.

106 Iwai A, Itoh M, Yokoyama Y, et al. Role of PAF in ischemia-reperfusion injury in the rat stomach. Scand $\mathcal{F}$ Gastroenterol [Suppl] 1989; 162: 63-6.

107 Bradley L M, Stambouly J J, Czaja J F, Goldstein R E. Influence of thromboxane A2 receptor antagonism on pulmonary vasoconstrictor responses. Pediatr Res 1989 ; 26: 175-9.

108 Mozes T, Braquet P, Filep J. Platelet activating factor: an endogeneous mediator of mesenteric ischemia-reperfusion induced shock. Am $\mathcal{f}$ Physiol 1989; 257: R872-7.

109 Lefer A M. Platelet activating factor (PAF) and its role in cardiac injury. Prog Clin Biol Res 1989; 301: 53-60.

110 Braquet P, Paubert-Braquet $M$, Koltai M, Bourgain $R$ Bussolino F, Hosford D. Is there a case for PAF antagonists in the treatment of ischemic states? Trends in Pharmacological Science 1989; 10: 23-30.

111 Morley J, Page C P, Paul W. Inflammatory actions of platelet-activating factor (PAF-acether) in guinea-pig skin. Br 7 Pharmacol 1983; 80: 503-9.

112 Archer C B, Page C P, Paul W, Morley J, McDonald D A. Inflammatory characteristics of platelet-activating factor (PAF-acether) in human skin. Br $\mathcal{F}$ Dermatol 1984; 110: 45-50.

113 Johnson A R, Erdos E G. Metabolism of vasoactive peptides by human endothelial cells in culture. Angiotensin I converting enzyme (kinase II) and angiotensinase. $\mathcal{F} \mathrm{Clim}$ Invest 1977; 59: 684-95.

114 Ody C, Junod A F. Converting enzyme activity in endothelial cells isolated from pig pulmonary artery and aorta. $A m$ F Physiol 1977; 232: C95-8.

115 Camussi G, Aglietta M, Malavasi F, et al. The release of platelet-activating factor from human endothelial cells in culture. F Immunol 1983; 131: 2397-403.

116 Krulewitz A H, Fanburg B L. The effect of oxygen tension on the in vitro production and release of angiotensinconverting enzyme by bovine pulmonary artery endothelial cells. Am Rev Respir Dis 1984; 130: 866-9.

117 King S J, Booyse F M, Lin P-H, Traylor M, Narkates A J Oparil S. Hypoxia stimulates endothelial cell angiotensinconverting enzyme antigen synthesis. Am f Physiol 1989; 256: C1231-8.

118 Jackson R M, Narkates J, Paril S. Impaired pulmonary conversion of angiotensin I to angiotensin II in rats
exposed to chronic hypoxia. $f$ Appl Physiol 1986; 60: exposed to chronic hypoxia. I Appl Physiol 1986; 60:

119 Veale $D$, Fitzgerald $O$. Serum and synovial fluid angiotensinconverting enzyme activity in inflammatory joint disease. Br 7 Rheumatol 1990; 29 (suppl) 23.

120 Knighton D R, Hunt T K, Scheuenstuhl H, Halliday B J Oxygen tension regulates the expression of angiogenesis factor by macrophages. Science 1983; 221: 1283-5.

121 Schaper W. The pathophysiology of myocardial perfusion. Amsterdam: Elsevier, 1979.

122 Kumar S, West D, Shahabuddin S, et al. Angiogenesis factor from human myocardial infarcts. Lancet 1984; ii:

123 Isenberg S J, McRee W E, Jedrzynski M S. Conjunctival hypoxia in diabetes mellitus. Invest Ophthalmol Vis $S \mathrm{Ci}$ 1988; 27: 1512-5.

124 Wagner W H, Weaver F A, Brinkley J R, Borchert M Lindsay $S \mathrm{~F}$. Chronic ocular ischemia and neovascular glaucoma: a result of extracranial carotid artery disease. $\mathcal{J}$ gasc Surg 1988; 8: 551-7.

125 Setty B N, Ganley C, Stuart M J. Effect of changes in oxygen tension on vascular and platelet hydroxyacid metabolites. II. Hypoxia increases 15-hydroxyeicosatetraenoic acid, a proangiogenic metabolite. Pediatrics 1985; 75: 911-5.

126 Koch A E, Polverini P J, Leibovich S J. Stimulation of 
neovascularization by human rheumatoid synovial tissue macrophages. Arthritis Rheum 1986; 29: 471-9.

127 Husby G, Williams R C Jr. Synovial localization of tumor necrosis factor in patients with rheumatoid arthritis. Fournal of Autoimmunity 1988; 1: 363-71.

128 Dusseau J W, Hutchins P M. Hypoxia-induced angiogenesis in chick chorioallantoic membranes: a role for adenosine. Respir Physiol 1988; 71: 33-44.

129 Morris P B, Ellis M N, Swain J L. Angiogenic potency of nucleotide metabolites: potential role in ischaemiainduced vascular growth. $\mathcal{f}$ Moll Cell Cardiol 1989; 21 : 351-8.

130 West D C, Hampson I N, Arnold F, Kumar S. Angiogenesis induced by degradation products of hyaluronic acid Science 1985; 228: 1324-6.

131 West D C, Kumar S. Hyanuronan and angiogenesis. In: Evered D, Whelan J, eds. The biology of hyaluronan. Chichester: Wiley, 1989: 187-207.

132 Brown R A, Weiss J B, Tomlinson I W. A ngiogenic factor from synovial fluid resembling that from tumours. Lancet 1980 ; i: $682-5$.

133 Brown R A, Tomlinson I W, Hill C R, Weiss J B, Phillips P, Kumar $S$. Relationship of angiogenesis factor in synovial fluid to various joint diseases. Ann Rheum Dis 1983; 42: 301-7.

134 Folkman J, Merler E, Abernathy C Williams G. Isolation of a tumour factor responsible for angiogenesis. $\mathcal{F} \operatorname{Exp} M e d$

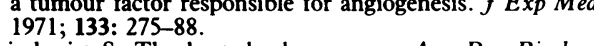

135 Lindquist S. The heat-shock response. Ann Rev Biochem 1986; 55: 1151-91.

136 Keyse S M, Tyrrell R M. Heme oxygenase is the major 32 KDa stress protein induced in human skin fibroblasts by UVA radiation, hydrogen peroxide, and sodium arsenite. Proc Natl Acad Sci USA 1989; 86: 99-103.

137 Sciandra J J, Subjeck J R, Hughes C S. Induction of glucose-regulated proteins after anaerobic exposure and of heat-shock proteins after reoxygenation. Proc Natl Acad Sci USA 1984; 81: 4843-7.

138 Guttman S D, Clover C V C, Allis C D, Grovsky M A. Heat shock, deciliation and release from anoxia induce the synthesis of the same set of polypeptides in starved T pyrifomis. Cell 1980; 22: 299-307.

139 Polla B S. A role for heat shock proteins in inflammation? Immunology Today 1988; 9: 134-7.

140 Winrow V R, McLean L, Morris C J, Blake D R. The heat shock protein response and its role in inflammatory shock protein response and its role in 